Article

\title{
Application of Ostrom's Social-Ecological Systems Framework in Nature Reserves: Hybrid Psycho-Economic Model of Collective Forest Management
}

\author{
Yi Xie ${ }^{1, *(1)}$, Yali Wen ${ }^{1}$ and Giuseppe T. Cirella ${ }^{2, *(1)}$ \\ 1 School of Economics and Management, Beijing Forestry University, Beijing 100083, China; \\ wenyali2003@163.com \\ 2 Faculty of Economics, University of Gdansk, 81-824 Sopot, Poland \\ * Correspondence: yixie@bjfu.edu.cn (Y.X.); gt.cirella@ug.edu.pl (G.T.C.)
}

Received: 23 September 2019; Accepted: 3 December 2019; Published: 5 December 2019

check for updates

\begin{abstract}
Nature reserves (NRs) are complex social-ecological systems (SESs). In China, many collective forests (CFs), owned by villagers, are bound within NRs. This paper aimed at carrying out a dynamic analysis of three case studies of CF management based on Ostrom's SES conceptual framework. The hybrid psycho-economic model is designed within this context and tested. Results indicate that CF management is determined jointly by the interaction of all levels of governance based on subsystem characteristics (i.e., resource system, resource units, and actor system) specific to the local social, economic, and political settings. Use of the hybrid psycho-economic model compares one classified harmonious NR scenario with two conflictual ones. The model indicated the scenario with the harmonious NR as having less CF value at the resource level, less dependence on villagers for CF resources, stronger environmental awareness, lower levels of involvement from new actors, overarching governance control (i.e., by the NR administration), greater levels of self-organization (i.e., within villages), and augmented economic compensation and regulation from outside influences. The conflict-oriented NRs mostly revealed opposite sets of interaction. Different public policies, including the ecosystem service payment, are recommended for improving management of CFs in NRs.
\end{abstract}

Keywords: collective forest; nature reserve; SES framework; community forest; Fujian Province; China

\section{Introduction}

Nature reserves (NRs) dominate protected areas in China. These are endowed, unique, and irreplaceable environments that exhibit an abundance of biodiversity, shelter endangered wildlife, promote public awareness of nature conservation, and have provided grounds for scientific research for more than five decades [1,2]. From 2014, China established 2729 NRs, covering approximately $15 \%$ of its terrestrial lands [3]. Currently, $80.7 \%$ of wild flora (i.e., vegetation) in China can be found within at least one NR $[1,4,5]$. The management system of these reserves, once focalized by top-down and command-and-control policy, has triggered a number of conflicts between local villagers and NR administration [6,7]. Prior to the 1990s, almost all NRs were managed in isolation, failing to incorporate local people or their interests $[8,9]$. This has created a negative attitude toward conservation among villagers and backlash from some engaged in the destruction of natural resources at the NR level $[10,11]$. Village desire for economic growth has further agitated the conflict in an effort to resolve widespread poverty [12,13]. Overlapping administrative management and executive control (i.e., 
instated via multiple government directives) has exacerbated these challenges, especially when multiple objectives have been simultaneously developed without prioritization [2]. As such, community-based co-management (CBCM) projects introduced in the mid-1990s (i.e., to conserve biodiversity, sustain the use of natural resources, and promote socioeconomic development of NRs and their surrounding villages) became the norm $[8,14,15]$. As more CBCM projects became implemented, a larger number of local organizations, established under local governments (i.e., administrative departments), have alleviated tensions between villages and NRs $[8,15]$. Since then, differing results have been observed throughout the country. It can be said that CBCM has worked well in some pilot NRs but not in others [16]. Widespread criticism suggests that, in practice, $\mathrm{CBCM}$ tends to gloss over the institutional complexities posed by the management of common-pool resources [17].

Complexities of NR management have gotten worse alongside fast-changing social, economic, and political environments enmeshed within the NR superstructure. The emergence of new users and formation of polycentric governance systems has increased the challenge of translating local knowledge within varying conservation-based scenarios. For example, in Romania, social network analysis applied to management actors as well as to the relationships among these actors revealed a low percentage of participation by locals and a marginal position to conservation organization in Natura 2000 protected areas [18,19]. However, since the late 1990s, conflicts centered around habitat loss in some NRs in South China show an increasing need for attention. The village-NR conflict arose in forests owned by villagers and, so-called, collective forests ( $\mathrm{CFs}$ ), which were designated as one part of an NR [20]. To date, there are government mandates in China that provide compensation to CF owners if losses are incurred, but reports, among varying NRs [2], note the amounts fail to match the loss [20,21]. The objective of this paper was to determine a general theoretic framework for use of Ostrom's social-ecological systems (SESs) within NRs. Moreover, to ensure a better understanding of different problems and solutions, we rely on case-based research. With the absence of a consolidated analytical framework, the objective spans to better understand the obstacle of properly conducting a comparative assessment on the performance of NRs, in general. One of the more useful frameworks for conservation biology is that of Ostrom's [22] SES analysis, which consists of the trifecta arrangement of bio-geo-physical units [23]. SES offers a balanced and nuanced approach to protected area management as well as a holistic framework for comparing and contrasting conservation successes and failures [24]. Its diagnostic nature can help identify case-specific variables, making cross-comparative research more accurate across cases [25].

To do so, this paper employs Ostrom's [22] SES framework to dynamically diagnose three cases of NR management in Fujian Province located in South China. Special attention is given to CF management where CFs account for a dominant portion of the NR. Three key contributions to current research are applied. First, the SES framework in relation to the NR and relevant villages incorporate both ecological and social-based scenarios. Second, interdisciplinary findings enable further national and transnational Sino-comparative research. Third, issues and concerns related to CF management in China's NRs are highlighted. The importance of this research stresses the gap in research that specifically investigates the management issues of CFs in NRs [16,26] in South China. To further the development of Ostrom's [22] SES framework, additional third-tier variables have been added to compensate for the social, economic, and political settings. This crucial higher tier analysis is the core aspect of how we utilize the framework. A breakdown of the paper is structured as follows: Section 2 gives a backdrop of CFs and NRs in China, Section 3 contains the methodology, Section 4 illustrates the results, Section 5 elucidates a discussion on the application and theoretical framing using Ostrom's [22] SES framework, and Section 6 provides the conclusion.

\section{Collective Forests and Nature Reserves in China}

In China, forests are categorized as CFs and state forests in terms of forestland ownership [27]. Villagers collectively own about $60 \%$ of the forestland while the rest is under state control [28]. Collective ownership of forestland was established in the 1950s and managed until the beginning 
of the 1980s [11]. The expanse of CFs inhabits large rural populations compared to state-owned forest areas. Spatially, the majority of CFs are located in southern China [2]. Correspondingly, in the mid-1950s, the NR system was established, with specific designation for hunting as well as logging bans in South China [29]. Since the 1980s, inspired by concepts of environmental protection from the United Nations Conference on the Human Environment [30], China's environmental policy has gradually been changing from a view of conquering nature to that of sustainable development-based thinking (i.e., the harmonious co-existence between human beings and nature itself) [31]. In 1993, China became a signatory party of the United Nations Convention of Biological Diversity; one year later, the first regulation on NRs, viz., Nature Reserves Regulations of the People's Republic of China, was enacted [32]. From the late 1990s to the beginning of the 21st century, both the number and total area of NRs in China increased rapidly [2]. As such, a newly established NR concept was put in place, i.e., large enough to ensure an integral ecosystem be protected, which typically meant larger than 10,000 ha. Dating back to China's 1985 directive "Management Measures for Nature Reserves of Forests and Wildlife", CFs were required to be incorporated into the newly established NRs. This action was primarily installed to avoid and reduce interference with local people [33] for a better co-managed co-existence. A nationwide inventory by the SFA [5] in 2013 for the first time revealed that 1385 NRs were made-up of CFs, accounting for $65.15 \%$ of NRs run by a centralized forestry administration. At the time, the area of CFs in the NRs amounted to 9.52 million ha, accounting for $7.76 \%$ of the total area of NRs. The inventory also disclosed that 9.49 million people lived in NRs, with 1.85 million living in national NRs and 7.66 million in provincial and county-level reserves.

In the early 1980s, the involvement of CFs in NRs was seen as a logical step, accepted by most villagers without much disapproval. Villagers were honored to contribute to state affairs. Both NR managers and village committees within reserve boundaries believed NRs were established and managed for public, ecological, and environmental benefits, and superior to just village-run entities. The villages were faithful followers of institutional arrangements set by the NRs. The communities and NRs operated as two economically independent and spatially isolated actors with inherently different interests with no apparent conflicts. However, from the 1980s, China has had several rounds of CF tenure reform [11,34], with its latest round being held in 2003. The reforms targeted security, right of usage, stability and benefits, and constraint for villages to transfer and lengthen management rights of CFs from village committees to individual households (i.e., with contracted terms from 30 to 70 years) [7]. The reforms have further inspired villagers to ask for other potential rights, impelling them with an endowment of more forest and higher revenue from forest usage. Forestland rights have become a key challenge confronting the whole process [21]. Management of CFs in NRs soon sprawled into the wider administrative challenge of not only the NR departments but all tiers of government. At present, the integration of CFs into NRs has not been fully incorporated and the vast majority of villages still lay claim to the importance of accurately marking out $\mathrm{CF}$ territory for compensation and territorial integrity.

\section{Methodology}

\subsection{Conceptual Framework: Social-Ecological System Analysis of Nature Reserves}

Without sufficient claim to CF territory, financial compensation, funded by the Ecological Forest Program and respectively hosted by the central and provincial governments, offsets economic loss of villages. Most villagers complain that the financial compensation standard is too low to cover their losses, with some villagers having been refused compensation all together (e.g., Liaoning Province) [1,27]. A number of conflicting viewpoints continue to center around the lack of attention CFs are given (i.e., with the most recent reform process), which negatively impacts the NR system. Irrespective, villagers living in the greater Beijing area and Zhejiang Province have reported satisfaction from the compensation fund [26]. As a result of these pronouncements, newly established NRs need to institute prior agreements with villages to build trust and incorporate rival views. To date, the 
relationship between NRs and village life is split by two standpoints. First, ongoing mass-scaled NR migration of rural surplus labor reduces village populations nationwide, thus alleviating stress and dependency on forest resources [35,36]. Second, in areas with newly developed tourism, infrastructure has grown to compensate for large spaces needed for guided tours and hiking, leading to illegal visitor access within NRs. These standpoints have not yet been resolved but illustrate a gap this paper (i.e., to some degree) confronts.

The NR system is a complex SES [24] designated to accurately describe specific ecological and cultural assets as well as provide essential ecosystem services that complement the core role in biodiversity conservation (Figure 1) [24,37,38]. Ostrom's [22] SES framework provides an integrative and multidisciplinary approach to understanding complex interaction within differing systems, scaled around natural resource governance $[39,40]$. The structure of the framework holds accurate to our objective and is adapted from McGinnis and Ostrom's [41] work and experimentation.

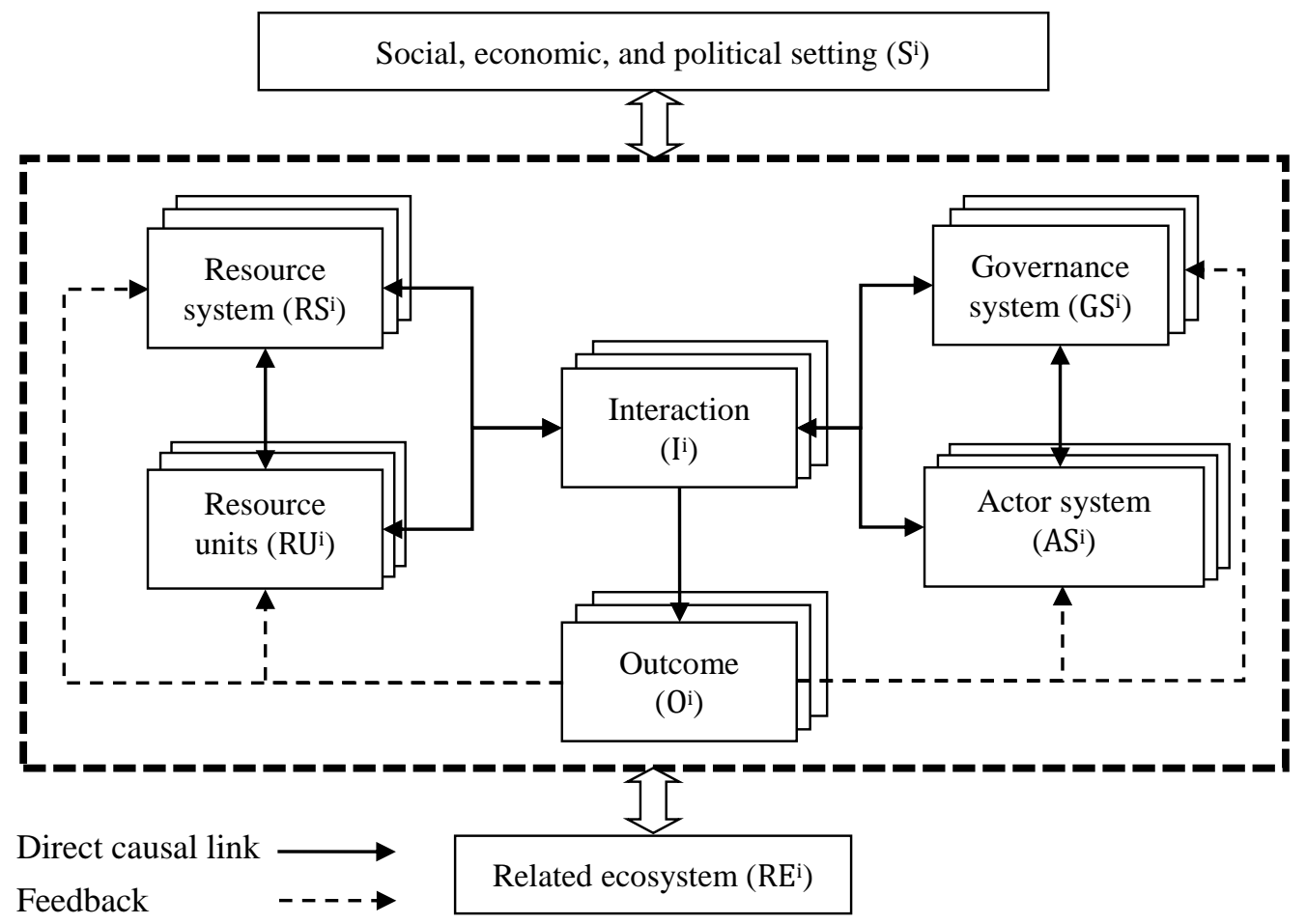

Figure 1. Core framework subsystems for analyzing SES of NRs, adapted from McGinnis and Ostrom [41]; 'i' = variable notation.

The study is broken down in terms of determining what outcome $\left(\mathrm{O}^{\mathrm{i}}\right)$ will be generated when CF management is implemented, where ' $\mathrm{i}$ ' refers to the variable notation. The outcome is classified into social performance, ecological performance, and externalities from other SES research [22]. We employ the relationship between NRs and relevant communities as a direct measure of the outcome. The relationship is categorized into two scenarios, i.e., harmonious and conflictual [42]. In the harmonious scenario, the NR and community positively coexist, complement, and benefit one another. On the contrary, in the conflictual scenario, the NR and community complain, accuse, and disagree as counterparts. The resource system $\left(\mathrm{RS}^{\mathrm{i}}\right)$ is a specified territory containing forest, wildlife, and other natural resources. The resource units $\left(\mathrm{RU}^{\mathrm{i}}\right)$, considered to be part of or beyond the resource system [41], consist of trees, fruits, seeds, medicinal herbs, mushrooms, bush meat, and other products found within the reserve. The resource system refers to unmovable and undivided stock while resource units refer strictly to flow extracted from stock [43]. In China, regulations on NRs prohibit all resource units from being extracted in core and buffer zones and limits them to experimental zones. As such, prudent use of resources encourages local participation in conservation, 
which NR administrators welcome, even though multiple functions of the resource system can cause NR management concerns. The actor system $\left(\mathrm{AS}^{\mathrm{i}}\right)$ defines actors affecting or affected by the resource system [44]. Villagers, inhabiting within and surrounding the NR, are traditionally and directly primary users sustaining their livelihood through resource extraction. Villagers are also major consumers of the resource units within NRs, while other types of consumers, such as tourists, increase their significant usage as reserves become more developed and accessible. Alongside tourists, tourism employees originating from outside of the reserve (i.e., conditional to tourism infrastructure), NGO staff, and academic researchers diversify user patterns. The governance system $\left(\mathrm{GS}^{\mathrm{i}}\right)$ incorporates characteristics of the local government, NR administration, village committees, relevant NGOs, regulatory measures from NR management, and local norms for natural resource use and extraction. Subsystems look into the processes through which decisions on SES management are made, implemented, reformed, and reinforced [44]. The process centers on actors who are guided by governance procedures that prohibit, permit, or require participation — at various hierarchical levels— to collectively act and, correspondingly, produce an outcome [40].

The social, economic, and political setting $\left(\mathrm{S}^{\mathrm{i}}\right)$ describes how the NR SES is affected or may affect the broader socio-economic, political, and ecological context in which they are embedded [44]. The attributes of this subsystem are comprehensive and complex to interpret. As a result, it is vital to clarify the setting (i.e., of the SES) due to unclear boundaries and, potential, externalities [44]. NRs located within a county, as well as those which span over more than one, follow a five-level top-down administrative hierarchical system in China. As such, most variables need to be defined at the county level within the relevant context [44]. The subsystem of the related ecosystem (RE ${ }^{\mathrm{i}}$, while less used in the existing literature, is also a challenge to identify. As a result, the conceptual framing observes the outcome as jointly determined by actors extracting resource units from the resource system, provisioning the maintenance of the resource system (i.e., in accordance with the regulations and procedures determined by the overarching governance), in the context of the related ecosystem and social, economic, and political setting. The extraction of resource units and the maintenance of the resource systems are major characteristics of the subsystem of interaction $\left(\mathrm{I}^{\mathrm{i}}\right)$.

In our scope to develop causable relationship between CF management and village net economic benefit, in relation to conservation [45,46], the SES framework falls short. It does, however, offer a close connection with collective action theory [47-49], common-pool resource theory [50-52], and game theory [53-55]. A recent study combined the SES framework with the NR-community conflict theory, revealing determinants of the conflicts in the Taibai Mountain National Reserve, China [56]. As a framework, SES provided the setting for contextual and process variables [40,57]. The conceptual idea is to elaborate the core framework subsystems and use them to analyze the SES of NRs by way of four parameters: Level of development, economic growth, conservation willingness, and relationship between NRs and village life. We can apply these parameters to measure (or interpret) the role of the SES in our study. In examining this matter, we developed a hybrid psycho-economic model built on the psychological orientation and eco-friendliness to economics (Figure 2). The hybrid psycho-economic model is founded on the basis of Liu et al.'s [42] relational categorization of harmonious versus conflictual scenarios. It is presented with reference to the three NR case studies investigated. 


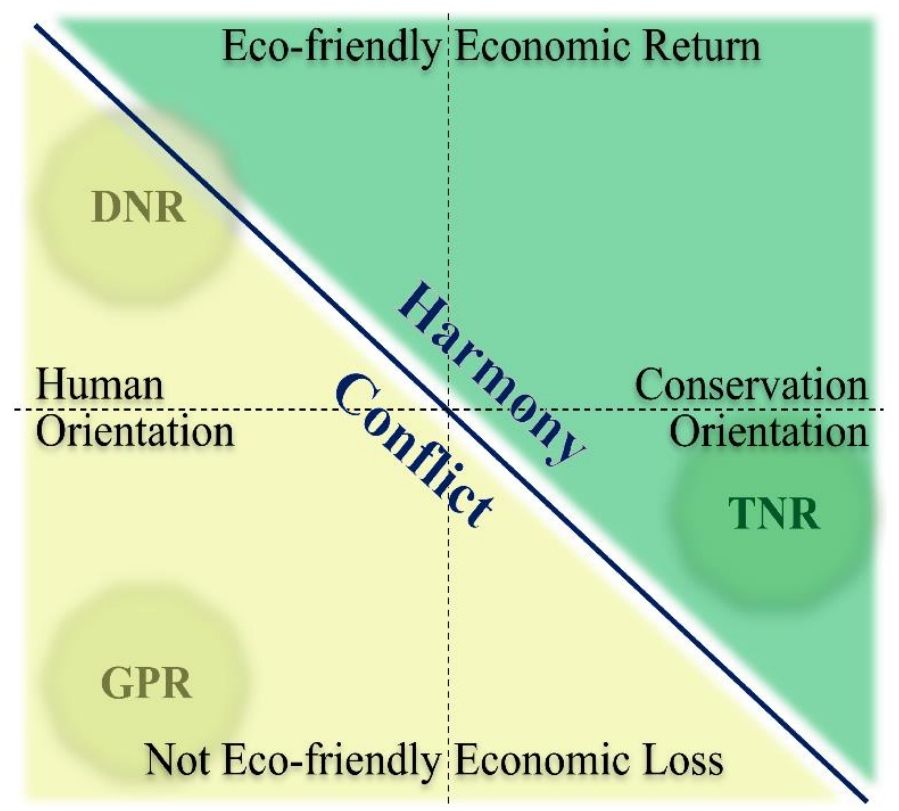

Figure 2. Hybrid psycho-economic model; TNR = Changting Tingjiangyuan National Nature Reserve; DNR = Dehua Daiyunshan National Nature Reserve; GPR = Fu'an Guaxisuoluo Provincial Nature Reserve.

\subsection{Study Area}

For the study, Fujian Province was selected due to the number of CFs located within its NRs. Fujian is located in South China and is top ranked nationwide in terms of forest coverage (i.e., 63\%) in which $89 \%$ are CFs [33]. As a pilot province in CF best practices, Fujian participated in the $2003 \mathrm{CF}$ reforms. At present, the province has 89 NRs, among which 15 are national nature reserves (NNRs), 21 provincial nature reserves (PNRs), 9 municipal level NRs, and 44 county-level NRs [58]. Three reserves were selected for the study: (1) Changting Tingjiangyuan National Nature Reserve (TNR) (i.e., a less developed reserve) facing minor economic loss, strong willingness to conserve nature, and strong levels of harmony; (2) Dehua Daiyunshan National Nature Reserve (DNR) (i.e., a medium developed reserve) fostering positive economic return, strong willingness to develop, and low levels of conflict; and (3) Fu'an Guaxisuoluo Provincial Nature Reserve (GPR) (i.e., a highly developed reserve) coping with large economic loss, very strong willingness to develop, and very high levels of conflict (Figure 3). The NRs were chosen from a workshop held in Fujian with NR management experts and officials as well as provincial administers in the first week of July 2018. Criteria for case selection relied on data representation and availability in conjunction with the hybrid psycho-economic model inference (i.e., each NR having a different harmony-conflict status). 


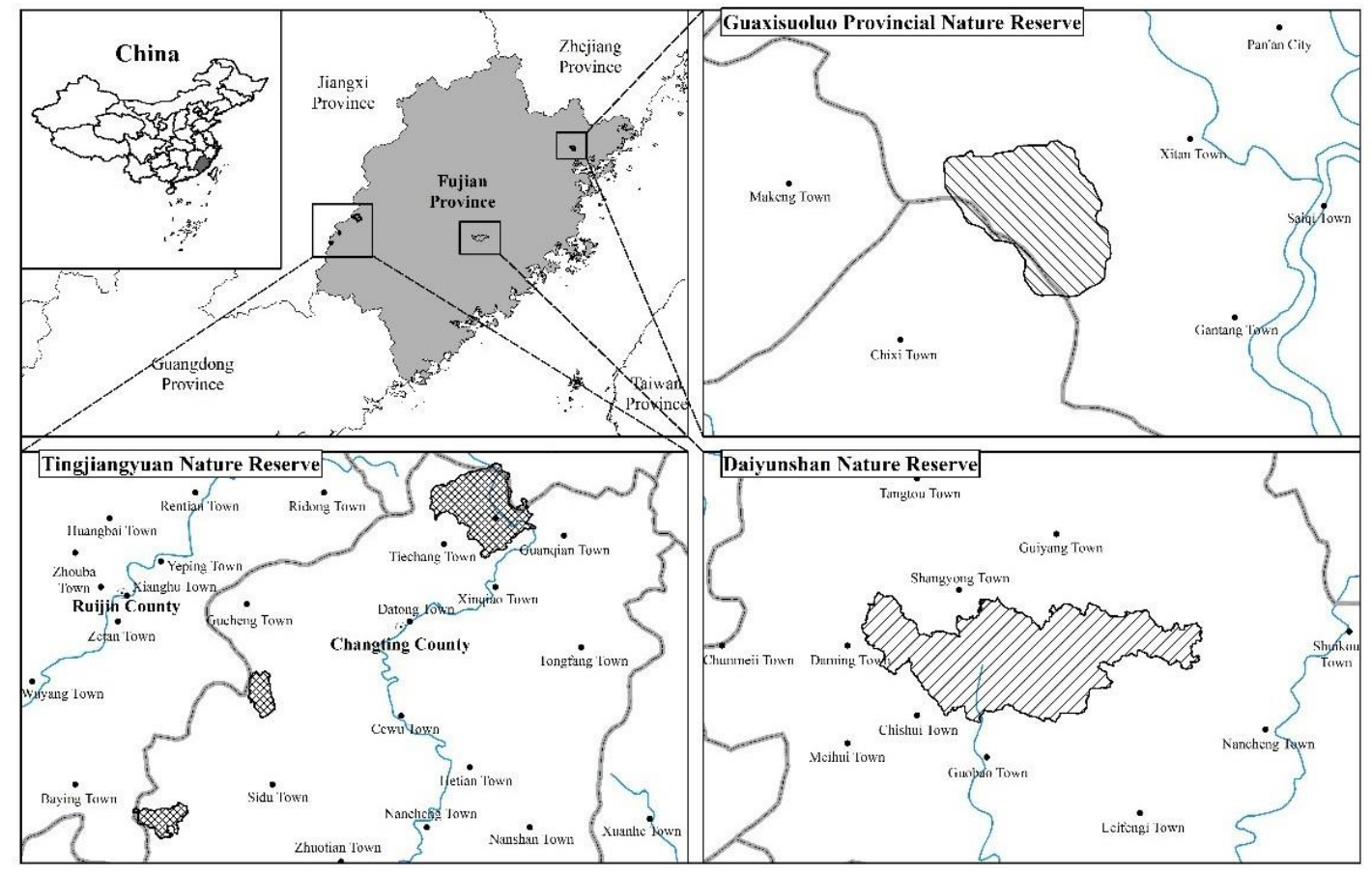

Figure 3. Geographic location of the three NR case studies in Fujian Province, China.

The social and economic characteristics of the counties and cities situated within the three case studies are heterogeneous in nature (Supplementary Table S1). Of the three, Changting County has the highest forest coverage, which is $2 \%$ higher than in Dehua County and $12 \%$ higher than Fu'an City. The average ratio of forestland versus rural inhabitants is smallest in Fu'an City and largest in Changting County. The gross domestic product (GDP) of Fu'an City ranks highest, dwarfing the other two counties twice over; however, the average gross domestic product (AGDP) of Dehua County tops Fu'an $C$ by $5 \%$ and Changting County by $40 \%$. The rural population with the highest net income per capita is found in Fu'an City while the lowest is in Changting; the income gap should also be noted as overwhelming. The rural population in the NRs has a much lower net income on average. It should be noted, in its favor, Changting County has unusually strict environmental policy in which curbing water and soil erosion as well as biodiversity conservation are emphasized.

\subsection{Variable Selection}

Based on the SES theoretic framework $[22,41,57,59]$ and associated empirical studies (e.g., Williams and Tai [40] and Delgado-Serrano and Ramos [44]), we defined 19 second-tier variables from six broad first-tier ones, and then further delineated 22 third-tier variables from the second-tier ones. The related ecosystem $\left(R E^{i}\right)$ from the first-tier variables was not incorporated due to the difficulty of diagnosing them in relation to the three NR case studies. The relevant secondary- and tertiary-level (i.e., profounder) variables were dependent on particular questions investigated, type of SES, and analyzed spatial and temporal scales [22]. One key inquiry to designing the study was to determine the outcome $\left(\mathrm{O}^{\mathrm{x}}\right)$ of the SES central to the NRs' handling of their CF area. The collective forest in the nature reserve (CFNR ${ }^{\mathrm{i}}$ ) is one sector of the NRs' resource system and is of primary concern. Among the nine second-tier variables identified by Ostrom [22], this study utilized only one variable for resource size $\left(\mathrm{CFRS}^{3}\right)$ to indicate the heterogeneity of the $\mathrm{CF}$ in different NRs. CFRS ${ }^{3}$ was decomposed into two third-tier variables: Ratio of CF in NR to the area of NR (CFRS $\left.{ }^{3 a}\right)$ and ratio of CF plantation in $\mathrm{NR}$ to the area of NR $\left(\mathrm{CFRS}^{3 \mathrm{~b}}\right)$. Moreover, we selected two second-tier variables, including resource value $\left(\mathrm{CFRU}^{4}\right)$ and number of units $\left(\mathrm{CFRU}^{5}\right)$, from the first-tier variable $C F$ resource units $\left(C F R U^{\mathrm{i}}\right)$. The number of units was further decomposed into two third-tier variables: Number of timber forestland $\left(\mathrm{CFRU}^{5 \mathrm{a}}\right)$ and number of bamboo forestland $\left(\mathrm{CFRU}^{5 b}\right)$. 
From the first-tier variable actor system $\left(\mathrm{AS}^{\mathrm{i}}\right)$, we selected four second-tier variables: Relevant actors $\left(\mathrm{AS}^{1}\right)$, socioeconomic attributes of users $\left(\mathrm{AS}^{2}\right)$, leadership $\left(\mathrm{AS}^{5}\right)$, and importance of resources $\left(\mathrm{AS}^{8}\right)$, followed by seven third-tier variables: Economic attributes of villagers $\left(\mathrm{AS}^{2 \mathrm{a}}\right)$, social attributes of villagers $\left(\mathrm{AS}^{2 \mathrm{~b}}\right)$, dependence on bamboo $\left(\mathrm{AS}^{8 \mathrm{a}}\right)$, dependence on other nature-based products (NBPs) $\left(\mathrm{AS}^{8 \mathrm{~b}}\right)$, and dependence on $\mathrm{CF}$ for tourism $\left(\mathrm{AS}^{8 \mathrm{c}}\right)$. From the first-tier variable governance system $\left(G S^{i}\right)$, we selected six second-tier variables: Government organization $\left(\mathrm{GS}^{1}\right)$, NGOs $\left(\mathrm{GS}^{2}\right)$, network structure $\left(\mathrm{GS}^{3}\right)$, property rights system $\left(\mathrm{GS}^{4}\right)$, operational rules $\left(\mathrm{GS}^{5}\right)$, and collective-choice rules $\left(\mathrm{GS}^{6}\right)$, as well as six second-tier variables: NR administration $\left(\mathrm{GS}^{1 \mathrm{a}}\right)$, village committee $\left(\mathrm{GS}^{1 \mathrm{~b}}\right)$, social network $\left(G^{3 a}\right)$, market network $\left(G S^{3 b}\right)$, rules for participatory conservation $\left(G^{5 a}\right)$, and rules for participatory alternative livelihood $\left(\mathrm{GS}^{5 b}\right)$. As recognition of the significant difference of the social and economic disparity in the selected study areas, we chose two second-tier variables from the first-tier social, economic, and political setting $\left(\mathrm{S}^{\mathrm{i}}\right)$. The second-tier variable of economic development $\left(\mathrm{S}^{1}\right)$ was formulated into two third-tier variables: AGDP $\left(S^{1 a}\right)$ and industrial structure $\left(S^{1 b}\right)$. The other second-tier variable government resources policies $\left(S^{2}\right)$ were broken down into three third-tier variables: Government regulatory and policy framework $\left(\mathrm{S}^{4 \mathrm{a}}\right)$, environmental policy $\left(\mathrm{S}^{4 \mathrm{~b}}\right)$, and compliance of environmental regulatory and policy framework $\left(\mathrm{S}^{4 \mathrm{c}}\right)$. Among 10 second-tier variables that stemmed from the first-tier variable interaction $\left(\mathrm{I}^{\mathrm{i}}\right)$, we selected information sharing $\left(\mathrm{I}^{2}\right)$, conflict resolution $\left(\mathrm{I}^{4}\right)$, investment activities $\left(\mathrm{I}^{5}\right)$, self-organizing activities $\left(\mathrm{I}^{7}\right)$, and networking activities $\left(\mathrm{I}^{8}\right)$.

\subsection{Data Collection}

A qualitative approach was used for data collection followed by a qualitative content analysis to code and analyze themes and patterns. Field data collection was carried out through a formal field survey from August to September 2018 (see Supplementary Table S2 and Supplementary Data S1 for sample questionnaires). A preliminary pilot survey was conducted beforehand in July 2018 to refine the survey plan. A series of semi-structured and structured interviews with key informants, including leaders and other cadres of village committees, elders, and prominent people in a clan as well as other parties (i.e., villagers hired by the NRs, ordinary villagers, officers of the NRs, officers in the county-level forestry department, staff members of relevant NGOs, tourism operators, and other stakeholders) was undertaken. Four focus group sessions were held: Three at the NR level and one at the provincial forestry administrative level. Focus group sessions were held in a participatory manner in which participants were encouraged to articulate historical evolution of subsystems within the NR SES (i.e., governance processes, resource dynamics, and use and institutional reform of $\mathrm{CFs}$ ). Independent observations were used to oversee interaction between villages and NRs as well as evaluative data pertaining to the $\mathrm{CF}$ management outcome. Collection also included informal publications about NR management, implementation of CBCM, CF tenure reform, and local educative development for recommendations and policy improvement.

Qualitative content analysis was used to code data and analyze the subject patterns. A quantitative method was employed to support the use of the qualitative analysis. In analyzing the variable of the size of the $\mathrm{CF}$ resource $\left(\mathrm{CFRS}^{3 \mathrm{a}}\right.$ ), we made a comparative analysis of the ratio of $\mathrm{CF}$ in the NR, in that it was identified as being extremely high if the ratio was larger than $80 \%$, and high if the ratio ranged between $60 \%$ and $80 \%$. To assess the CF resource value (CFRU ${ }^{4}$ ), we synthesized responses from villagers and NRs to get a primary result. We further collected information about forest types, forest stock, forest quality, and unit market price, and used them to testify the results on the CF resource value. The identified actors $\left(\mathrm{AS}^{\mathrm{i}}\right)$ were based on the interviews, second-hand data collected from relevant yearbooks, and our own independent field observations. To evaluate leadership $\left(\mathrm{AS}^{5}\right)$ and its association with CF management outcomes, we analyzed three outcomes: (1) Major events held by the leader of the village committees, (2) trust of villagers in their leader, and (3) attitude of NRs to the leader. Strong leadership was inferred by the head of a village for leading collective action and balancing village development with nature conservation as well as villager livelihood. Further explanation of this variable is elaborated upon within the literature $[41,51,57]$ and the results. Note, some sampling bias 
should be considered, since the three NR case studies investigate all three different types of CBCM and compared them across cases [38]. The assessment also allowed for the examination of SES framework variables by cross-scale and cross-level interactions occurring over time. That, in and of itself, makes it difficult to isolate specific variables as well as their causal relationship in determining outcomes [40].

\section{Results}

CF management is a core part of NR SES management; it is an ongoing interactional process in which outcomes are determined jointly by the interactions at all levels of governance (i.e., they are based upon characteristics of the resource system, resource units, and actors) in the context of the specified social, economic, and political settings. A breakdown of the three NR SESs indicate that subsystems vary and differ from one another. The analyzed results for the NR SESs are itemized using the core framework subsystems in tabular format.

\subsection{Community Forest Resource System and Resource Units}

All three NR case studies had a higher ratio of CF embedded within their NR area (CFRS $\left.{ }^{3 a}\right)$. Features of each CF differed as seen in Table 1. In TNR, the CF accounted for $72.1 \%$, with a size of 7488.1 ha in comparison to all land and $76.5 \%$ of total forestland. A small portion of CF (i.e., 221 ha) exists as plantation, with the remainder in a state of natural regeneration. The plantation consists of 8 ha of bamboo and 213 ha of timber forest. Bamboo is ranked as the top source of cash (i.e., income) for villagers. In DNR, the CF accounted for $86.6 \%$, with a size of $11,661.5$ ha of all land, with $89.9 \%$ total forestland. A total of 1137 ha is plantation and the remainder CFs are under the state of natural regeneration. The CF plantation consists of 47.7 ha of bamboo, 1088.48 ha of timber forest, and 0.82 ha of shrubs. In GPR, all forests (i.e., amount to $1289.83 \mathrm{ha}$ ) are collectively owned, of which $91.5 \%$ (i.e., 1179.8 ha) are planted by villagers for individual investment. The forest plantation consists of 152.6 ha of bamboo, 917.1 ha of timber forest, and 110.1 ha of shrubs. The timber forests have matured and are of high economic value $\left(\mathrm{CFRU}^{4}\right)$. Villagers continue traditional practices by producing non-timber products, such as medical herbs, tea, mushrooms, and honey, for cash and subsistence. Resource dependence varied across TNR, DNR, and GPR $\left(\mathrm{AS}^{8}\right)$. In TNR, local villagers had a low dependence on CF resources in the NR with a relatively low cash income. In DNR, local villagers had a high dependence on indirect use of the $\mathrm{CF}$ for tourism and cash income $\left(A S^{8 \mathrm{c}}\right)$, which meant less reliance on bamboo and other NBPs for cash income and subsistence $\left(\mathrm{A}^{8 \mathrm{a}}, \mathrm{AS}^{8 \mathrm{~b}}\right)$. In GPR, local villagers had a strong dependence on the direct use of timber $\left(\mathrm{CFRU}^{4}\right)$ and bamboo $\left(\mathrm{AS}^{8 \mathrm{a}}\right)$.

Table 1. Comparison of resource system $\left(R S^{i}\right)$ and resource units $\left(R U^{i}\right)$ in TNR, DNR, and GPR.

\begin{tabular}{|c|c|c|c|c|c|}
\hline Notation & Variable & Working Definition & TNR & DNR & GPR \\
\hline CFRS $^{\mathrm{i}}$ & $\begin{array}{l}\text { Community forest } \\
\text { resource system }\end{array}$ & \multirow{5}{*}{$\begin{array}{c}\text { Ratio of CF in NR to NR area } \\
\text { Area of collective forest } \\
\text { plantation in the NR }\end{array}$} & & & \\
\hline CFRS $^{3}$ & Size & & & & \\
\hline CFRS $^{3 a}$ & Ratio CF in NR:NR & & High & Extremely high & Extremely high \\
\hline $\mathrm{CFRS}^{3 \mathrm{~b}}$ & Ratio CF plantation:CF in NR & & Low & Somewhat low & High \\
\hline CFRU $^{\mathrm{i}}$ & Community forest resource units & & & & \\
\hline CFRU $^{4}$ & Resource value & \multirow{2}{*}{$\begin{array}{l}\text { Economic value of the } \\
\text { collective forest resource }\end{array}$} & Low & High & High \\
\hline CFRU $^{5}$ & Number of units & & & & \\
\hline CFRU $^{5 a}$ & Number of timber forest & $\begin{array}{l}\text { Total number of collective } \\
\text { timber forest resource }\end{array}$ & Low & High & High \\
\hline CFRU $^{5 b}$ & Number of bamboo forest & $\begin{array}{l}\text { Total number of collective } \\
\text { bamboo forest resource }\end{array}$ & Low & Medium & High \\
\hline
\end{tabular}

\subsection{Actor System}

Among the three NR SESs, actors varied significantly while dependence on CF resources was mixed (Table 2). TNR spans across 5 townships and 15 administrative villages affiliated to Changting County (i.e., 12 administrative villages that are partially located within the NR, totaling 36,812 villagers, 
and 3 villages fully located within the NR, totaling 4420 villagers). Most villagers lived along the buffer and experimental zones, with less than $10 \%$ living within the core. Most villagers have a similar source of income, such as off-farm work, crop cultivation, and bamboo harvesting. A high number of direct users of the $\mathrm{CF}\left(\mathrm{A}^{1 \mathrm{a}}\right)$ usually generate potentially high forest dependence and stress, which echoes the village dependence on bamboo $\left(\mathrm{A}^{8 \mathrm{a}}\right)$. DNR spans across 6 townships and 22 administrative villages affiliated with Dehua County. There are 20 administrative villages that share a border crossing with the NR, with 31,774 villagers, and 2 villages located solely within the NR, with 2200 villagers. Most villagers live off farming, crop cultivation, and bamboo harvesting. Rapid development of tourism is also prevalent; as such, tourists $\left(\mathrm{A}^{1 \mathrm{~b}}\right)$, as indirect users, have increased rapidly in recent years, which has led to a high dependence on expanding the $C F$ tourism market $\left(A^{8 C}\right)$. GPR spans over two townships and seven administrative villages. None of the administrative villages are completely located within the PNR; however, 10 natural villages (i.e., one tier lower than an administrative village) are inside it. The total population is 5796, of which 4236 villagers live in the PNR and 1561 near it. All five villages have common features of a lesser developed economy.

Table 2. Comparative results from the actor system (ASi) in TNR, DNR, and GPR.

\begin{tabular}{|c|c|c|c|c|c|}
\hline Notation & Variable & Working Definition & TNR & DNR & GPR \\
\hline $\mathrm{AS}^{1}$ & Relevant actors & & & & \\
\hline $\mathrm{AS}^{1 \mathrm{a}}$ & $\begin{array}{l}\text { Direct users of natural } \\
\text { resources }\end{array}$ & $\begin{array}{l}\text { Number of direct users } \\
\text { of the CF per } \mathrm{m}^{2}\end{array}$ & Medium & Low & High \\
\hline $\mathrm{AS}^{1 \mathrm{~b}}$ & Other actors & $\begin{array}{c}\text { Number of tourists in } \\
\text { the NR }\end{array}$ & Slow growth & Rapid growth & Slow growth \\
\hline $\mathrm{AS}^{2}$ & $\begin{array}{l}\text { Socioeconomic attributes } \\
\text { of users }\end{array}$ & & & & \\
\hline $\mathrm{AS}^{2 \mathrm{a}}$ & Economic attributes & $\begin{array}{l}\text { Economic condition of } \\
\text { villagers }\end{array}$ & Mostly poor & $\begin{array}{l}\text { Few wealthy, } \\
\text { mostly middle } \\
\text { class }\end{array}$ & Mostly poor \\
\hline $\mathrm{AS}^{2 \mathrm{~b}}$ & Social attributes & $\begin{array}{l}\text { Ratio of adults failed to } \\
\text { afford marriage }\end{array}$ & Low & Low & High \\
\hline $\mathrm{AS}^{5}$ & Leadership patterns & $\begin{array}{l}\text { Ability of village head } \\
\text { committee to lead } \\
\text { collective action }\end{array}$ & Strong & Strong & Weak \\
\hline $\mathrm{AS}^{8}$ & Resource importance & & & & \\
\hline $\mathrm{AS}^{8 \mathrm{a}}$ & Dependence on bamboo & $\begin{array}{l}\text { Villager dependence on } \\
\text { bamboo for livelihood }\end{array}$ & High & Low & High \\
\hline $\mathrm{AS}^{8 \mathrm{~b}}$ & $\begin{array}{l}\text { Dependence on other } \\
\text { NBPs }\end{array}$ & $\begin{array}{l}\text { Villager dependence on } \\
\text { other NBPs for } \\
\text { livelihood }\end{array}$ & $\begin{array}{l}\text { Mostly } \\
\text { medium }\end{array}$ & Mostly low & $\begin{array}{l}\text { Mostly } \\
\text { medium }\end{array}$ \\
\hline $\mathrm{AS}^{8 \mathrm{c}}$ & $\begin{array}{c}\text { Dependence on CF for } \\
\text { tourism }\end{array}$ & $\begin{array}{l}\text { Villager dependence on } \\
\text { CF for tourism }\end{array}$ & Low & High & Low \\
\hline
\end{tabular}

\subsection{Governance System}

Both TNR and DNR administrations are stronger and more independent than GPR (GS $\left.{ }^{1 a}\right)$. In line with the leadership of the village head $\left(\mathrm{A}^{5}\right)$, the capacity of village committees in TNR and DNR is higher than that of GPR. TNR's administration began as an affiliate to Changting's forestry administration. Three years after its promotion, CNR's administration became an independent organization of the Changting County government (i.e., in 2017), one tier higher than the county forestry administration and township government. DNR's administration was established, along with being designated an NNR, in 1985 and is affiliated with the Dehua County government (i.e., with minimal executive authority). Along with an NNR upgrade in 2015, DNR administrators are direct subordinates to the county government, one tier higher than the county forestry administration and township government. The GPR administration was initially established as a division affiliated to the Fu'an Forestry Administration Bureau in 1996. Soon after, in 1999, it was upgraded to a PNR in which the division has remained the same ever since. The PNR administration is one tier lower than the executive setting of township governments. Finally, non-governmental organizations (NGOs), as a whole, play a positive role in the management of CFs throughout much of the NR; for example, there 
are multiple NGOs that promote CF management within TNR and some that reduce conflicts in DNR. In GPR, however, their absence may be reflective of severe conflict and lack of mediation (Table 3).

Table 3. Comparison of the governance system $\left(G S^{i}\right)$ in TNR, DNR, and GPR.

\begin{tabular}{|c|c|c|c|c|c|}
\hline Notation & Variable & Working Definition & TNR & DNR & GPR \\
\hline $\mathrm{GS}^{1}$ & $\begin{array}{l}\text { Government } \\
\text { organization }\end{array}$ & & & & \\
\hline $\mathrm{GS}^{1 \mathrm{a}}$ & NR administration & $\begin{array}{l}\text { Tier for authority of the } \\
\text { NR administration }\end{array}$ & National & National & Provincial \\
\hline $\mathrm{GS}^{1 \mathrm{~b}}$ & Village committee & $\begin{array}{c}\text { Capacity of the village } \\
\text { committee }\end{array}$ & Strong & Strong & Weak \\
\hline $\mathrm{GS}^{2}$ & NGOs & Presence of NGOs & $\begin{array}{l}\text { Present - } \\
\text { Multiple }\end{array}$ & $\begin{array}{l}\text { Present -Some } \\
\text { types }\end{array}$ & Absent \\
\hline $\mathrm{GS}^{3}$ & Network structure & & & & \\
\hline $\mathrm{GS}^{3 \mathrm{a}}$ & Social networks & $\begin{array}{l}\text { Vertical and horizontal } \\
\text { partners in } \\
\text { co-management }\end{array}$ & Strong & Strong & Weak \\
\hline $\mathrm{GS}^{3 \mathrm{~b}}$ & Market networks & $\begin{array}{l}\text { Vertical and horizontal } \\
\text { partners in commence }\end{array}$ & Weak & Strong & Strong \\
\hline $\mathrm{GS}^{4}$ & Property rights system & $\begin{array}{l}\text { Restriction on villager } \\
\text { rights to CF use }\end{array}$ & Partially & Partially & Largely \\
\hline $\mathrm{GS}^{5}$ & Operational rule & & & & \\
\hline $\mathrm{GS}^{5 \mathrm{a}}$ & $\begin{array}{l}\text { Rules for participatory } \\
\text { conservation }\end{array}$ & $\begin{array}{l}\text { Rule for village } \\
\text { participation in } \\
\text { conservation }\end{array}$ & Strong & Medium & Weak \\
\hline$G S^{5 b}$ & $\begin{array}{l}\text { Rules for participatory } \\
\text { alternative livelihood }\end{array}$ & $\begin{array}{c}\text { Rule for village } \\
\text { participation in } \\
\text { determining alternative } \\
\text { livelihoods }\end{array}$ & Strong & Medium & Weak \\
\hline $\mathrm{GS}^{6}$ & Collective-choice rules & $\begin{array}{l}\text { Rules defined by actors } \\
\text { according to local } \\
\text { environmental, } \\
\text { economic, and political } \\
\text { condition }\end{array}$ & Strong & Medium & Weak \\
\hline
\end{tabular}

In terms of network structure, a robust social network in TNR and DNR contributes to nature conservation $\left(\mathrm{GS}^{3 \mathrm{a}}\right.$ ) while strong market networks in DNR and GPR provide incentives to exploit nature resources $\left(\mathrm{GS}^{3 \mathrm{~b}}\right)$. In TNR, operational rules encourage and guarantee villages the ability to participate in nature conservation and encourage alternative sources of income $\left(\mathrm{GS}^{5 \mathrm{a}}, \mathrm{GS}^{5 \mathrm{~b}}\right)$; however, in GPR, such operational rules are hardly observed. Collective-choice rules in TNR are also strong through effective decision-making mechanisms at the NR SES level.

\subsection{Social, Economic, and Political Setting}

This study analyzed variables of social, economic, and political settings $\left(\mathrm{S}^{\mathrm{i}}\right)$, which supplies an understanding on how SESs operate and influence exogenous factors (Table 4). Executively, Fu'an City is at the same setting as Changting County and Dehua County. Fu'an City's population is larger than the other two and fosters advanced secondary and tertiary industries. In terms of the AGDP, Changting County is much less developed than Dehua County and Fu'an City $\left(\mathrm{S}^{1 \mathrm{a}}\right)$. Dehua County, on the other hand, is undeveloped agriculturally, instead focusing on tourism development, which encourages villagers in the NRs to explore $\mathrm{CF}$ tourism $\left(\mathrm{S}^{1 \mathrm{~b}}\right)$. 
Table 4. Comparison of the social, economic, and political setting $\left(\mathrm{S}^{\mathrm{i}}\right)$ in TNR, DNR, and GPR.

\begin{tabular}{|c|c|c|c|c|c|}
\hline Notation & Variable & Working Definition & TNR & DNR & GPR \\
\hline$S^{1}$ & Economic development & & & & \\
\hline$S^{1 \mathrm{a}}$ & AGDP & $\begin{array}{c}\text { GDP value per capita in } \\
2018\end{array}$ & Low & Medium & Medium \\
\hline$S^{1 b}$ & Industrial structure & $\begin{array}{l}\text { Importance of the } \\
\text { tourism industry }\end{array}$ & Medium & Extremely high & Medium \\
\hline$S^{4}$ & $\begin{array}{l}\text { Government resource } \\
\text { policy }\end{array}$ & & & & \\
\hline$S^{4 a}$ & $\begin{array}{l}\text { Government regulatory } \\
\text { and policy framework }\end{array}$ & $\begin{array}{l}\text { Governmental } \\
\text { regulatory and policy } \\
\text { framework for natural } \\
\text { resource management }\end{array}$ & $\begin{array}{l}\text { Strong and } \\
\text { effective }\end{array}$ & $\begin{array}{l}\text { Strong and } \\
\text { medium }\end{array}$ & $\begin{array}{l}\text { Weak and } \\
\text { medium }\end{array}$ \\
\hline$S^{4 b}$ & Environmental policy & $\begin{array}{l}\text { Level of implementation } \\
\text { and policy direction }\end{array}$ & $\begin{array}{l}\text { Extremely } \\
\text { strong }\end{array}$ & Strong & Weak \\
\hline$S^{4 c}$ & $\begin{array}{l}\text { Compliance of } \\
\text { environmental } \\
\text { regulatory and policy } \\
\text { framework }\end{array}$ & $\begin{array}{l}\text { Compliance of } \\
\text { inhabitants to } \\
\text { governmental regulation, } \\
\text { policy, and management }\end{array}$ & Strong & Medium & Weak \\
\hline
\end{tabular}

Resource-based policy at the county and higher levels has significant impacts on properly managing CFs throughout the NRs. Development policy boosts village motivation to expand the tourism industry in DNR $\left(S^{4 a}\right)$. The stringent policies in environmental protection in TNR $\left(\mathrm{S}^{4 \mathrm{~b}}\right)$ enable inhabitants and other actors to follow governmental regulatory and policy for NR management $\left(\mathrm{S}^{4 \mathrm{c}}\right)$ when CF-based activities are implemented $\left(\mathrm{AS}^{1 \mathrm{~b}}\right)$. An observed issue that requires attention is overly enthusiastic tourism development, which can create conflict with NR management in Dehua County.

\subsection{Interaction}

While subsystems, such as the resource system, resource units, actor system, and governance system, provide the backbone for the NR SES' interactions ( $\left.\mathrm{I}^{\mathrm{i}}\right)$, including: Information sharing, deliberation process, conflict resolution, investment activities, self-organizing activities, and networking activities, the determined outcome is condition-specific. The results illustrate findings from the six interactions, linking relevant variables in the three NR case studies (Table 5).

Table 5. Comparison of interaction $\left(\mathrm{I}^{\mathrm{i}}\right)$ in TNR, DNR, and GPR.

\begin{tabular}{|c|c|c|c|c|c|}
\hline Notation & Variable & Working Definition & TNR & DNR & GPR \\
\hline $\mathrm{I}^{2}$ & Information sharing & $\begin{array}{c}\text { Sourcing to keep communication between NRs } \\
\text { and villages }\end{array}$ & Strong & Strong & Weak \\
\hline $\mathrm{I}^{3}$ & Deliberation process & Deliberation for alternative livelihoods & Present & Present & Absent \\
\hline$I^{4}$ & Conflict resolution & $\begin{array}{l}\text { Workshop or dialogue to address conflict and } \\
\text { reach amenable conclusions }\end{array}$ & Present & Present & Absent \\
\hline $\mathrm{I}^{5}$ & Investment activities & Building of human and resource capacity in SES & Strong & Medium & Weak \\
\hline
\end{tabular}

Information sharing. In TNR and DNR, information sharing $\left(\mathrm{I}^{2}\right)$ was active through well-operated village committees $\left(\mathrm{GS}^{1 b}\right)$ under strong leadership $\left(\mathrm{AS}^{5}\right)$. The presence of NGOs $\left(\mathrm{GS}^{2}\right)$ also facilitated information sharing through environmental awareness, education, and outreach for villagers. Both Changting County and Dehua County had sound government regulatory and policy action for the management of natural resource $\left(\mathrm{S}^{4 b}\right)$ and effective environmental policy $\left(\mathrm{S}^{4 \mathrm{c}}\right)$, which benefitted the NR and villages. However, GPR's weak leadership, i.e., the head of the village committee (AS ${ }^{5}$, $\left.\mathrm{GS}^{1 b}\right)$, absence of NGO support $\left(\mathrm{GS}^{2}\right)$, and ineffective regulatory and policy implementation $\left(\mathrm{S}^{4 \mathrm{a}}, \mathrm{S}^{4 \mathrm{~b}}\right)$ jointly resulted in limited information sharing among actors $\left(\mathrm{AS}^{1 \mathrm{a}}, \mathrm{AS}^{1 \mathrm{~b}}\right)$.

Deliberation process. Due to weak leadership and self-governance in the associated villages $\left(A S^{5}, G^{1 b}\right)$, the lower tier executive setting for GPR $\left(\mathrm{GS}^{1 \mathrm{a}}\right)$, undeveloped social networks $\left(\mathrm{GS}^{3 \mathrm{~b}}\right)$, and operational rules that failed to convince villagers $\left(\mathrm{GS}^{5 a}, \mathrm{GS}^{5 b}\right)$ strained the effectiveness of the 
deliberation process in GPR SES. As such, operational rules $\left(\mathrm{GS}^{5 a}, \mathrm{GS}^{5 b}\right)$ did not align with the development of the villages and villager livelihood (i.e., CF management could not be modified through the deliberation process $\left.\left(\mathrm{I}^{3}\right)\right)$. Conversely, the presence of valid deliberation in CNR and DNR contributed to the prevention and alleviation of CF management conflict $\left(\mathrm{I}^{4}\right)$ and successfully integrated a number of alternative livelihood options for villagers by reducing the dependence on natural resources $\left(\mathrm{A}^{8 \mathrm{a}}, \mathrm{A}^{8 \mathrm{~b}}\right)$.

Conflict resolution. Conflict in DNR and GPR has been more intensive than in TNR for more than two decades. It was found that the ratio of CF in DNR and GPR was higher than in TNR (CFRS ${ }^{3 a}$ ). As such, correlative findings of CF plantations, for instance, in GPR at 78\%, were a major cause of the conflict under $\mathrm{CF}$ management $\left(\mathrm{CFRS}^{3 \mathrm{~b}}\right)$. The high economic value of CF resources for DNR $\left(\mathrm{CFRU}^{4}\right)$ are dependent on the rapidly increasing tourism industry $\left(\mathrm{AS}^{1 \mathrm{~b}}\right)$, supported by the local county government $\left(\mathrm{S}^{1 \mathrm{~b}}\right)$. In TNR, a set of tools $\left(\mathrm{GS}^{5 \mathrm{a}}, \mathrm{GS}^{5 \mathrm{~b}}\right)$, consisting of dialogue, workshops, and mediation, organized by the co-management committee, play an active role in resolving its conflicts. Moreover, conflict resolution $\left(\mathrm{I}^{4}\right)$ gained support from regulatory laws and policies at the county level $\left(\mathrm{S}^{4 \mathrm{a}}, \mathrm{S}^{4 \mathrm{~b}}, \mathrm{~S}^{4 \mathrm{c}}\right)$. The conflicts in DNR seem to be more complex, in that appeals from villagers to develop tourism have been prioritized. In GPR, the conflicts were even more complex due to the low compliance of villagers in obeying governing rules, absence of valid tools to alleviate high pressure conflicts, and strong appeal to harvesting timber from the CF plantation (i.e., the issue that has predominantly overshadowed much of the discord).

Investment activities. Investment activities $\left(\mathrm{I}^{5}\right)$, including building human capacity and improving resource quality, were strong in TNR and DNR but weak in GPR, as NNRs (GS $\left.{ }^{1 a}\right)$, i.e., TNR and DNR, received free training and entrepreneurial opportunities organized by the central government. Financial investment also covered improving the condition of natural resources and their value $\left(\mathrm{CFRU}^{4}\right)$. Historical and on-going project development that combats against water and soil erosion $\left(\mathrm{S}^{4 b}\right)$ contributes to enhancing leadership TNR-wide $\left(\mathrm{AS}^{5}\right)$. The village heads in DNR stressed strong leadership as fundamental to tourism promotion $\left(\mathrm{S}^{4 a}, \mathrm{AS}^{5}\right)$. The Fu' an City government mostly funded GPR with a limited budget and financial support package from the provincial-level government.

Self-organizing activities. The primary self-organization $\left(\mathrm{I}^{7}\right)$, viz., the village committee, existed in all villages in all three NR case studies. The village committees played different roles in CF management in each of the NRs, including diverse leadership by committee heads $\left(\mathrm{AS}^{5}\right)$ and collective action as actors $\left(\mathrm{GS}^{6}\right)$. In GPR, the weak role of the village committee in CF management determined much of the property rights system $\left(\mathrm{GS}^{4}\right)$, conflict intensity, and environmental regulatory and policy framing $\left(\mathrm{S}^{4 \mathrm{a}}, \mathrm{S}^{4 \mathrm{~b}}, \mathrm{~S}^{4 \mathrm{c}}\right)$. The co-management committee in DNR played a less positive role in CF management even though it possessed the same strong self-organizing capacity as TNR. It can be presumed, since the villagers in DNR had higher intentions to make use of the CFs for tourism, and not strictly for conservation, a discrepancy in self-organization has been established.

Networking activities. Within both TNR and DNR, multi-tier and multi-scale networks with the NR administrative bodies $\left(\mathrm{GS}^{1 \mathrm{a}}\right)$, village committees $\left(\mathrm{GS}^{1 \mathrm{~b}}\right)$, and relevant executive departments at the county and higher levels as well as NGOs $\left(\mathrm{GS}^{2}\right)$ were built, creating a strong networking environment. The presence of several NGOs expanded network capacity by interlinking and leveraging resources to strengthen CF management in the respective NR. In comparison, weak leadership in GPR resulted in a weak structured network and a poor level of support (i.e., resulting in ineffective management of the CF $\left(\mathrm{AS}^{5}\right)$ ). However, it is worth noting that TNR had a unique social network, consisting of Hakka people from abroad, offering an immigrant support system that the CF management could utilize $\left(\mathrm{GS}^{3 a}\right)$.

\subsection{Outcome}

In terms of outcome $\left(\mathrm{O}^{\mathrm{i}}\right)$, TNR had strong CF management developed via strong leadership of village committees, effective prevention, and conflict resolution mechanisms. Its strong self-organization and collective action, appropriate dependence on CF resources without negative impact on the NR, 
horizontal-vertical social network, and sound social, economic, and political setting made for a harmonious scenario. In DNR, CF management experienced low-to-medium levels of conflict caused by disparity between the booming tourism industry and $\mathrm{CF}$ management regulations in the reserve. In GPR, CF management faces severe conflict centered on CF plantations located within the NR and recent strife with overdevelopment.

\section{Discussion}

Application of Ostrom's [22] SES framework supplied a precise diagnostical experiment of three case studies of CF management in NRs $[41,57,59]$. The implementation of the framework identified vital processes and contextual variables as well as their interactions associated with $\mathrm{CF}$ management outcomes. Derived from the existing literature, this study explored several three-tier contextual variables and first-tier variables of social, economic, and political settings in which the adaptive process complimented the SES framework. As such, this work can assist in developing the framework by building a classification of variables related to CF management and NR best practices. The application of Ostrom's [22] diagnostic framework reveals that management of CFs in NRs is a process of self-organization, networking, conflict resolution, and capacity-building within specific conditions jointly determined by social, economic, and political factors.

Notedly, McGinnis and Ostrom [41] contended that the SES framework is theory neutral even though early studies of the framework relate to the common pool resource theory and public governance theory [41]. Multiple-tier variables channel the analysis by presenting, instead of explaining, different CF management outcomes formed in each of the three NR cases. The hybrid psycho-economic model enables us to set up a causable relationship between the CF management outcome and process and contextual variables. In the hybrid model, psychological orientation and economic impact differentiate village attitudes to NRs, which have a determinate impact on CF management. The psychological orientation and economic impact of the villagers are formed in the dynamic process of the relevant SES. For example, villagers in TNR are conservation orientated due to long-term environmental campaigns supported by central and provincial governments. Confronted with economic loss by inadequate compensation to the CF within TNR, villagers continue to have a semi-negative attitude within the NR. To this sense, the psychological perspective is overdrawn by physical shortage. This is a new finding compared to existing research that links SES and NR-community conflict theory [56]. Human orientation and psychological perspective, however, require additional observation to overhaul the prevailing development economics dominating much of rural China. In comparison, villagers from DNR and GPR have the same human orientation and belief system (i.e., psychological perspective), but suffer much more in terms of economic hardship. Hence, it can be said that CF management is more of a problem in these conflict areas rather than in TNR. The differences in economics for each of the three NR case studies form the interactive process between each of the SES subsystems. The seven interactions in TNR are in good operation with sound performance, which is rooted in the effectiveness of the governance at the actor level—especially in terms of resource utilization. Compared to TNR, villagers both in DNR and GPR are restricted in terms of resource utility, which creates severe economic loss.

The act of NR reservations is not solely to foster sustainability [40]. NRs are complex and dynamic systems with much uncertainty. All subsystems are in the process of evolution, which jointly determines the operation of the whole SES. Each subsystem interacts with the other, affecting the outcome as a collective unit. Policymakers need to deepen their understanding of the complexity of socially and ecologically oriented NR systems to enhance sustainability. CF management problems are rooted in the connectivity of CFs within NRs. As such, more appropriate economic compensation is needed to offset economic loss caused by CFs, especially for the NRs with abundant CF plantations. The poverty of villagers in NRs should attain more attention from NR authorities and the government in general. For example, villagers in GPR are easily affected by market demand and prone to exploitative forces. As such, alternative income needs to be created with active participation of local villagers in line with sound nature conservation. Village leaders play an important role in village development and nature 
conservation since they are usually better informed and have more involvement in capacity building. Finally, increasing the participation of the local population will provide a more stable social structural foundation of adaptation and transformation in overall SES sophistication (i.e., framing) [60].

Next, the vertical and horizontal networks also need to be developed further. At the vertical perspective, NRs should be supported from higher levels of government and foster stronger capacity for autonomy (i.e., self-organization) and collective choice below the village level. At the horizontal, multiple government departments should be organized to establish a cooperative management council for conflict resolution in CF management, reinforcement of NR management, and promotion of harmonious activities between village development and nature conservation. Additional NGOs should be engaged in promoting environmentally friendly development and furthering nature conservation by way of positive modelling via NR SES management. The integration of all actors will promote collaborative environmental governance to minimize environmental impact [61]. In terms of the dynamic characteristics of SES, a monitoring system is needed to understand the evolutionary process of NR SES as well as offer supplementary evidence for NR SES best practices and management.

This study developed the theoretic framing of SES by way of empirical research. Involvement of the social, economic, and political settings is a subtle extension of the practical application of a SES framework. Further studies are needed in the following two fields. First, social networks (GS $\left.{ }^{3 a}\right)$ at the village level are very complex intensive, in that informal social norms in rural China must be respected. Thus, villagers often originate from different clans and follow household (i.e., family) rules versus the village head. That is, the presence of multiple families and clans in one village can create a complex problematic horizontal network. Second, the analysis of relevant actors $\left(\mathrm{AS}^{1}\right)$ can be improved by enlarging the size and scale of the NR SES. This would enlarge the number of shareholders making direct and indirect use of natural resources, resulting in better system results. It should be noted that features from direct and indirect users differ from each other. Attributes with social and economic backing should be carefully assessed and differentiated. As such, we agree with Ostrom's [22] conclusion that no panacea solution for natural resource management exists; however, each case and relevant study, when treated uniquely, adds to the knowledge base and SES framework puzzle.

\section{Conclusions}

As a diagnostic study, we presented different CF management settings in NRs based on Ostrom's SES framework. The application of the hybrid psycho-economic model provided an explanation for the differing results of CF management for each SES. Among the three NR case studies reviewed, TNR had a harmonious relationship in terms of CF management; however, DNR experienced low-to-medium levels of conflict and GPR was severe. The different outcomes of CF management are determined by the interaction of villagers' psychological orientation and economic effect, which determines the dynamic processes of the SES. We explored typically important impacts on environmental policy-a third-tier variable of the social, economic, and political setting-regarding the formulation of villages' psychological orientation. We found that the increasing actors, especially new actors, along with the restriction of expanding resource utilization, lead to conflict as seen in DNR. For GPR, serious conflict occurred due to hostility by villagers toward the NR and the severe economic loss of mature forest plantations within the reserve area.

Different from a traditional study with a static review [23], the SES framework enabled this study to follow a dynamic perspective of the research, in which changing conditions may have influenced the CF outcome. Hence, this expanded the concept of resource use, patterns of interaction, and institutional interplay by illuminating influences within the NR management outcome [40]. Due to the weak governance capacity at the NR administrative level, e.g., the hostile attitude from DNR villagers, a lack of mitigation measures is a partial problem. As such, over the course of the study, the forest plantation increased in value, further aggravating hostility, and thus demanding that the NR administration prioritizes more resources in resolving the issue. At present, the NR administration is working on piecing together capable means of resolving this matter-creating something that is often 
called a dead loop [62]. Conversely, a similar cycle existed in the SES for TNR. In all, the application of Ostrom's [22] SES framework addresses the issue of absence, a common analytical framework that natural resource managers have been improving upon for the better part of a decade. The selection of variables and tier settings has nuanced differences in empirically run experimentation, sparking research gaps in the SES framework as well as future development needs. Moreover, in terms of NRs in China, feasible economic compensation for villagers affected by CFs in NRs-accompanied by a sound environmental lifestyle—should be prioritized as the top issue.

Supplementary Materials: The following are available online at http://www.mdpi.com/2071-1050/11/24/6929/s1, Table S1: Primary information of the sample nature reserves, Table S2: Questionnaire on collective forest management in national nature reserve, Data S1: Questionnaire on management and utilization of national nature reserve and surrounding communities and collective forests.

Author Contributions: Conceptualization, Validation, Formal analysis, Writing_-original draft preparation: Y.X. and Y.W. Investigation, Methodology, Resources, Writing — review and editing: Y.X. and G.T.C.

Funding: This research is supported by the Fundamental Research Funds from Central University under Grant No.: 2018BLRD001.

Acknowledgments: The authors are grateful to Peichen Gong, Yaoqi Zhang, and Samuel K. Wasser for reviewing and providing us with excellent feedback. The first author is especially grateful to the Center for Conservation Biology, University of Washington, Seattle, WA, USA, for hosting him as a Fulbright Visiting Scholar.

Conflicts of Interest: The authors declare no conflict of interest.

\section{References}

1. Wu, R.; Zhang, S.; Yu, D.W.; Zhao, P.; Li, X.; Wang, L.; Yu, Q.; Ma, J.; Chen, A.; Long, Y. Effectiveness of China's nature reserves in representing ecological diversity. Front. Ecol. Environ. 2011, 9, 383-389. [CrossRef]

2. Zhang, L.; Luo, Z.; Mallon, D.; Li, C.; Jiang, Z. Biodiversity conservation status in China's growing protected areas. Biol. Conserv. 2017, 210, 89-100. [CrossRef]

3. Xu, H.; Cao, M.; Wang, Z.; Wu, Y.; Cao, Y.; Wu, J.; Le, Z.; Cui, P.; Ding, H.; Xu, W.; et al. Low ecological representation in the protected area network of China. Ecol. Evol. 2018, 8, 6290-6298. [CrossRef] [PubMed]

4. Ministry of Ecology and Environment. China's Fourth National Report on the Implementation of the Convention on Biological Diversity; China Environmental Publishing House: Beijing, China, 2014.

5. State Forestry Administration. China Forestry Statistic Yearbook; China Forestry Press: Beijing, China, 2014. (In Chinese)

6. Lane, M.B. Affirming New Directions in Planning Theory: Comanagement of Protected Areas. Soc. Nat. Resour. 2001, 14, 657-671. [CrossRef]

7. Wen, Y.; Xie, Y. Analysis on characteristics of bio-diversity resource property right and their influence on conservation in China (in Chinese with English abstract). J. Beijing For. Univ. (Soc. Sci.) 2009, 8, 87-92.

8. Xie, Y.; Yang, S.; Wen, Y.; Su, W. Study on the status of conservation and management and the suggestion on countermeasures for the Hainan Bawangling National Nature Reservein. For. Resour. Manag. 2009, 3, 22-26, (In Chinese with English Abstract).

9. Foggin, J.M. Managing Shared Natural Heritages: Towards More Participatory Models of Protected Area Management in Western China. J. Int. Wildl. Law Policy 2014, 17, 130-151. [CrossRef]

10. Harkness, J. Recent Trends in Forestry and Conservation of Biodiversity in China. China Q. 1998, 156, 911-934. [CrossRef]

11. Xie, Y.; Gong, P.; Han, X.; Wen, Y. The effect of collective forestland tenure reform in China: Does land parcelization reduce forest management intensity? J. For. Econ. 2014, 20, 126-140. [CrossRef]

12. Zhou, D.Q.; Grumbine, E.R. National parks in China: Experiments with protecting nature and human livelihoods in Yunnan province, Peoples' Republic of China (PRC). Biol. Conserv. 2011, 144, 1314-1321. [CrossRef]

13. Xu, W.; Gao, J.; Xia, X.; Zhou, D.; Li, Z.; Jiang, M. Distribution of Community Residents in Nature Reserves and Its Impacts on the Reserves in China. J. Ecol. Rural Environ. 2016, 32, 19-23.

14. Yang, J.; Jin, L.; Wang, L. Co-management in community from the perspective of development intervention. Rural Econ. 2008, 10, 42-45, (In Chinese with English abstract). 
15. Zhu, T.; Shivakoti, G.P.; Haiyun, C.; Maddox, D. A survey-based evaluation of community-based co-management of forest resources: A case study of Baishuijiang National Natural Reserve in China. Environ. Dev. Sustain. 2012, 14, 197-220.

16. Weng, Q.; Xie, Y. Study on conflicts in management of collective forests in the nature reserves of China. For. Resour. Manag. 2016, 3, 23-27, (In Chinese with English abstract).

17. De Pourcq, K.; Thomas, E.; Arts, B.; Vranckx, A.; Léon-Sicard, T.; Van Damme, P. Conflict in Protected Areas: Who Says Co-Management Does Not Work? PLoS ONE 2015, 10, e0144943. [CrossRef]

18. Manolache, S.; Nita, A.; Ciocanea, C.M.; Popescu, V.D.; Rozylowicz, L. Power, influence and structure in Natura 2000 governance networks. A comparative analysis of two protected areas in Romania. J. Environ. Manag. 2018, 212, 54-64. [CrossRef]

19. Nita, A.; Ciocanea, C.M.; Manolache, S.; Rozylowicz, L. A network approach for understanding opportunities and barriers to effective public participation in the management of protected areas. Soc. Netw. Anal. Min. 2018, 8, 31. [CrossRef]

20. Xu, J.; Melick, R. Rethinking the Effectiveness of Public Protected Areas in Southwestern China. Conserv. Biol. 2007, 21, 318-328. [CrossRef]

21. Wei, W.; Xie, Y.; Yu, S. Study on current institution and countermeasures for solving the tenure disputes of collective forests: A case study in a county of Jiangxi province. J. Beijing For. Univ. (Soc. Sci.) 2016, 15, 48-53, (In Chinese with English abstract).

22. Ostrom, E. A General Framework for Analyzing Sustainability of Social-Ecological Systems. Science 2009, 325, 419-422. [CrossRef]

23. Berkes, F. Evolution of co-management: Role of knowledge generation, bridging organizations and social learning. J. Environ. Manag. 2009, 90, 1692-1702. [CrossRef] [PubMed]

24. Cumming, G.S.; Allen, C.R. Protected areas as social-ecological systems: Perspectives from resilience and social-ecological systems theory. Ecol. Appl. 2017, 27, 1709-1717. [CrossRef] [PubMed]

25. Basurto, X.; Gelcich, S.; Ostrom, E. The social-ecological system framework as a knowledge classificatory system for benthic small-scale fisheries. Glob. Environ. Chang. 2013, 23, 1366-1380. [CrossRef]

26. Si, P.; Xie, Y.; Wang, C.; Wen, Y. Study on ecological compensation mechanism for collective forests in nature reserve in China. For. Econ. 2015, 9, 101-105, (In Chinese with English abstract).

27. Zhang, Y.; Uusivuori, J.; Kuuluvainen, J. Impacts of economic reforms on rural forestry in China. For. Policy Econ. 2000, 1, 27-40. [CrossRef]

28. State Forestry Administration. China Forestry Statistic Yearbook; China Forestry Press: Beijing, China, 2010. (In Chinese)

29. Wang, S.; Xie, Y.; Schei, P. China's Protected Area; Tsinghua University Press: Beijing, China, 2004.

30. UN Environment Programme (UNEP). Declaration of the United Nations Conference on the Human Environment; United Nations Environmental Programme: Stockholm, Sweden, 1972.

31. Liu, J.; Diamond, J. China's environment in a globalizing world. Nature 2005, 435, 1179-1186. [CrossRef]

32. State Council of PRC. Nature Reserves Regulation of the People's Republic of China; State Council of PRC: Beijing, China, 2005. (In Chinese)

33. State Forestry Administration. China Forestry Statistic Yearbook; China Forestry Press: Beijing, China, 2018. (In Chinese)

34. Xie, Y.; Wen, Y.; Zhang, Y.; Li, X. Impact of property rights reform on household forest management investment: An empirical study of southern China. For. Policy Econ. 2013, 34, 73-78. [CrossRef]

35. Duan, W.; Zhao, Z.; Liu, M.; Wen, Y. Study on the dependence of natural resource in nature reserve and communities surrounding. J. Agrotech. Econ. 2016, 3, 93-102, (In Chinese with English Abstract).

36. Duan, W.; Wen, Y. Impacts of protected areas on local livelihoods: Evidence of giant panda biosphere reserves in Sichuan Province, China. Land Use Policy 2017, 68, 168-178. [CrossRef]

37. DeFries, R.; Pagiola, S.; Adamowicz, W.L.; Akcakaya, H.R.; Arcenas, A.; Babu, S.; Balk, D.; Confalonieri, U.; Cramer, W.; Falconi, F. Analytical Approaches for Assessing Ecosystem Condition and Human Well-being. In Ecosystems and Human Well-Being: Current State and Trends, Volume 1; Hassan, R., Scholes, R., Ash, N., Eds.; Island Press: Washington, DC, USA; Covelo, CA, USA; London, UK, 2005; pp. 37-71. 
38. Basurto, X.; Jiménez-Pérez, I. Institutional Arrangements for Adaptive Governance of Biodiversity Conservation: The Experience of the Area de Conservación de Guanacaste, Costa Rica. J. Lat. Am. Geogr. 2013, 12, 111-134. [CrossRef]

39. Epstein, G.; Vogt, J.M.; Mincey, S.K.; Cox, M.; Fischer, B. Missing ecology: Integrating ecological perspectives with the social-ecological system framework. Int. J. Commons 2013, 7, 432. [CrossRef]

40. Williams, K.; Tai, H.S.; Williams, K.W.; Tai, H.S. A Multi-Tier Social-Ecological System Analysis of Protected Areas Co-Management in Belize. Sustainability 2016, 8, 104. [CrossRef]

41. McGinnis, M.D.; Ostrom, E. Social-ecological system framework: Initial changes and continuing challenges. Ecol. Soc. 2014, 19, art30. [CrossRef]

42. Liu, J.; Ouyang, Z.; Miao, H. Environmental attitudes of stakeholders and their perceptions regarding protected area-community conflicts: A case study in China. J. Environ. Manag. 2010, 91, 2254-2262. [CrossRef] [PubMed]

43. Ostrom, E. Governing the Commons: The Evolution of Institutions for Collective Action; Cambridge University Press: Cambridge, UK, 1990; ISBN 0521405998.

44. del Mar Delgado-Serrano, M.; Ramos, P. Making Ostrom's framework applicable to characterise social ecological systems at the local level. Int. J. Commons 2015, 9, 808. [CrossRef]

45. McDermott, M.H.; Schreckenberg, K. Equity in community forestry: Insights from North and South. Int. For. Rev. 2009, 11, 157-170. [CrossRef]

46. Yiwen, Z.; Liu, J. Principal-agent relationships in rural governance and benefit sharing in community forestry: Evidence from a community forest enterprise in China. For. Policy Econ. 2019, 107, 101924. [CrossRef]

47. Ido, A. The effect of social capital on collective action in community forest management in Cambodia. Int. J. Commons 2019, 13, 777. [CrossRef]

48. García-López, G.; Antinori, C. Between Grassroots Collective Action and State Mandates: The Hybridity of Multi-Level Forest Associations in Mexico. Conserv. Soc. 2018, 16, 193. [CrossRef]

49. Rout, S. Collective Action for Sustainable Forestry. Soc. Chang. 2010, 40, 479-502. [CrossRef]

50. Timilsina, R.R.; Kotani, K.; Kamijo, Y. Sustainability of common pool resources. PLoS ONE 2017, 12 , e0170981. [CrossRef] [PubMed]

51. Ostrom, E. Chapter 24 Common-pool resources and institutions: Toward a revised theory. Handb. Agric. Econ. 2002, 2, 1315-1339.

52. Fleischman, F.D.; Loken, B.; Garcia-Lopez, G.A.; Villamayor-Tomas, S. Evaluating the utility of common-pool resource theory for understanding forest governance and outcomes in Indonesia between 1965 and 2012. Int. J. Commons 2014, 8, 304. [CrossRef]

53. Silva, R.R.; Gomes, L.; Albuquerque, U. Plant extractivism in light of game theory: A case study in northeastern Brazil. J. Ethnobiol. Ethnomed. 2015, 11, 6. [CrossRef] [PubMed]

54. Frank, D.M.; Sarkar, S. Group Decisions in Biodiversity Conservation: Implications from Game Theory. PLoS ONE 2010, 5, e10688. [CrossRef]

55. Carlson, L.J.; Wilson, P.I. Beyond zero-sum: Game theory and national forest management. Soc. Sci. J. 2004, 41, 637-650. [CrossRef]

56. Zhang, Y.; Hu, Y.; Zhang, B.; Li, Y.; Zhang, X.; Xie, Y. Conflict between nature reserves and surrounding communities in China: An empirical study based on a social and ecological system framework. Glob. Ecol. Conserv. 2020, 21, e00804. [CrossRef]

57. Ostrom, E. A diagnostic approach for going beyond panaceas. Proc. Natl. Acad. Sci. USA 2007, 104, 15181-15187. [CrossRef]

58. Department of Wildlife Conservation and Nature Reserve Administration (DWCNRA). Statistic Yearbook of Nature Reserve Attached to Forestry Administration in National Wide; Department of Wildlife Conservation and Nature Reserve Administration, SFA: Beijing, China, 2017.

59. Ostrom, E.; Cox, M. Moving beyond panaceas: A multi-tiered diagnostic approach for social-ecological analysis. Environ. Conserv. 2010, 37, 451-463. [CrossRef]

60. Barnes-Mauthe, M.; Gray, S.A.; Arita, S.; Lynham, J.; Leung, P. What Determines Social Capital in a Social-Ecological System? Insights from a Network Perspective. Environ. Manag. 2015, 55, 392-410. [CrossRef] 
61. Bodin, Ö.; Sandström, A.; Crona, B. Collaborative Networks for Effective Ecosystem-Based Management: A Set of Working Hypotheses. Policy Stud. J. 2017, 45, 289-314. [CrossRef]

62. Najafi, M.; Hosseinnia, S.; Sheikholeslam, F.; Karimadini, M. Closed-loop control of dead time systems via sequential sub-predictors. Int. J. Control 2013, 86, 599-609. [CrossRef] 